\title{
An investigation of drive summation in a water runway
}

JACK B. ROLLINS AND ROGER K. THOMAS, UNIVERSITY OF GEORGIA NORMAV R. REMLEY, UNIVERSITY OF FLORIDA MEDICAL. SCHOOL

\begin{abstract}
Abstraet
Three groups of rats ran at each temperature, $15^{\circ}$ and $37.5^{\circ} \mathrm{C}$, for three days. Two groups were $72 \mathrm{hr}$. food deprived the first day; one group was reinforced with food in addition to escape reinforcement. These groups were $23 \mathrm{hr}$. deprived the second and third days. Significant differences occurred between temperatures and days.
\end{abstract}

\section{Problem}

Morey (1934) found speed of swimming and efficiency of learning in a water maze were enhanced by the presence of a loud buzzer; this experiment gave the first indication of drive summation in a water escape task. Braun, Wedekind \& Smudski (1957) found that the addition of $22 \mathrm{hr}$. food deprivation resulted in significantly faster learning in a water escape, Lashley III maze; this faster learning occurred at temperatures of $15^{\circ}$ and $35^{\circ}$ C. Finally, Levine, Staats, \& Frommer (1959) shocked their experimental animals with $0.8 \mathrm{ma}$ for $20 \mathrm{sec}$. and observed their swimming behavior as compared to non-shocked controls. The shocked animals escaped faster in both a straight runway and a simple maze. The water was said to be at room temperature.

The present investigation studied the effects of rewarded and non-rewarded food deprivation in a straight water runway. Two temperatures of water were used, $15^{\circ}$ and $37.5^{\circ} \mathrm{C}$.

\section{Method}

The Ss were 36 male, albino rats between the ages of 90 and 120 days. They were divided into two main groups corresponding to water temperatures of $15^{\circ}$ and $37.5^{\circ} \mathrm{C}$. Of these main groups, each was divided into three subgroups designated the reinforced (R), the non-reinforced (NR), and the control group (C).

The apparatus was a grey, $12 \mathrm{ft}$ long tank with a width and depth of $1 \mathrm{ft}$. At one end of the tank, a wire mesh platform was constructed with a ramp leading to the platform. Water temperature was easily maintained within one degree of the desired value by the addition of warm water or ice as needed. No bits of ice were allowed in the tank at the same time a rat was in it.

Seventy-two hr. prior to the first trial, the $\mathrm{S}$ was deprived of food if it belonged to either the $\mathrm{R}$ or NR group; C rats were never deprived. Before each day's trials, $S$ was placed on the escape platform for $1 \mathrm{~min}$. If the rat belonged to the $\mathrm{R}$ or $\mathrm{C}$ groups, a standard lab chow pellet was available in a small dish on the platform. After this exploration period, $\mathrm{S}$ was removed to a cage for $1 \mathrm{~min}$. prior to its first trial. At the start of a trial, the rat was lowered into the water facing the platform. $\mathrm{S}$ was then allowed $2 \mathrm{~min}$. to escape; if it did not escape, it was returned to the home cage to await the next trial $1 \mathrm{~min}$. later. If the rat escaped, it was allowed to remain on the platform $15 \mathrm{sec.}$, during which it could eat the food if it was in the $\mathrm{C}$ or $\mathbf{R}$ groups. There was a $1 \mathrm{~min}$. interval between trials.

Swimming times were measured by stop watch, and the number of times the food was taken was recorded. Five trials were given each day for three consecutive days. At the end of each day's trials, the rats which had been deprived of food prior to the experiment were allowed to eat for $1 \mathrm{hr}$. or a maximum of about 12-15 gm; consequently, they were $23 \mathrm{hr}$. deprived for the second and third days of the experiment.

\section{Resulis}

A three-way analysis of variance with repeated measures on one of the factors was computed. The analysis indicated that the only significant differences occurred between temperature of water $(p<.05)$ and days $(p<.01)$. Multiple comparisons tests showed the differences in temperature to be significant on all days. The significant difference between days occurred only between the first and second days.

Table 1 shows mean swimming times for the three groups of rats at each temperature condition for the three days. The grand mean of all groups each day of the experiment may be seen beneath the title "Mean." The data were determined after elimination of a rat in the NR group of the $37.5^{\circ} \mathrm{C}$ condition which failed to escape on any trial of day one. This was the only rat to give such a performance.

The $\mathrm{R}$ group took the food $63 \%$ of the time in the $37.5^{\circ}$ condition and $33 \%$ of the time in the $15^{\circ}$ condition. The C group never took the food.

\section{TABLE I}

SWIMMING TIME IN SECONDS FOR THE THREE GROUPS OF EACH WATER TEMPERATURE

\begin{tabular}{ccrrrr} 
Groups & \multicolumn{1}{c}{ R } & NR & C & Mean \\
\hline \multirow{2}{*}{ Temperature } & Days & & & & \\
$37.5^{\circ} \mathrm{C}$ & 1 & 21.2 & 22.4 & 31.6 & 25.1 \\
& 2 & 11.3 & 9.4 & 11.8 & 10.3 \\
& 3 & 3.3 & 9.3 & 11.2 & 9.9 \\
$15 \mathrm{C}$ & 1 & 18.5 & 21.0 & 16.9 & 13.3 \\
& 2 & 3.6 & 3.1 & 3.6 & 3.4 \\
& 3 & 3.3 & 7.1 & 9.7 & 3.4
\end{tabular}




\section{Discussion}

The apparent discrepancy between the present study and the previous studies which indicated that drive summation occurs in the water escape task can probably be explained on the basis of the complexity of the tasks used. The studies by Morey (1934) and Braun et al (1957) used mazes. The study by Levine et al (1959) cannot be so simply explained, since they too used a straight runway. It will be recalled that they ran their Ss in water at room temperature, and they used pretrial shock to "activate" the animals. It has been shown in the present study that swimming was not at an asymptote in the warmer temperature, so it is reasonable that more activated animals could perform faster. The effects of pre-trial shock are apparently greater than the effects of $72 \mathrm{hr}$. pre-trial food deprivation. It remains to be seen whether shock prior to swimming will enhance swimming speed in $15^{\circ} \mathrm{C}$ water.

It seemed apparent that by the second day learning was complete and performance was the only variable

\section{A method of measuring brain lesions ROGER K. THOMAS, JR, AND L. J. PEACOCK UNIVERSITY OF GEORGIA}

\begin{abstract}
It was noted that the most frequently used method of measuring brain lesions is probably the planimeter. The planimeter method is time consuming and planimeters are not readily available to most psychologists. The dot grid method was described and recommended for its savings in effort and expense with negligible sacrifice of accuracy.
\end{abstract}

\section{Problem}

Cartographers (Robinson, 1953) and foresters (Spurr, 1948; Avery, 1962) have devised several methods of determining the area of irregular fields. Psychologists sometimes need to determine irregular areas as in the case of cortical ablations. The majority of psychologists using rats as Ss have employed Lashley brain diagrams (1929) to determine the amount of cortex removed. The most frequent method used is that of determining area with a planimeter. This is a preferred method for its accuracy, but it is time consuming, and the planimeter is an expensive instrument. Some psychologists have used weight apportioning methods, but this is very time consuming and has less accuracy. An alternative to both these techniques that psychologists have apparently overloaked is the dot grid method. This is inexpensive, quick and accurate. There are other techniques available for area determination, but the present writers wish to describe and recommend the dot grid method.

\section{Method}

Avery (1962) noted that dot grids can be purchased or improvised inexpensively. One commercially available dot grid was prepared and described by Bryan (1943), and this can be purchased at forestry supply houses. A dot grid can be improvised by marking a transparent then being studied. It must be concluded that the deprivation levels used in this experiment do not enhance performance in the water escape runway; however, the data concerning the number of times the food was taken indicated that the food had different value in the two temperature conditions. Specifically, the food was sought less after the experience in the colder water, indicating the rats were more "concerned" with other things after being in the cold water. It should be recalled that after the first day the animals were less deprived, and it could be that increasing the deprivation period prior to the second and third experimental days would produce different results.

\section{References}

Braun, H. W., Wedekind, C. E., \& Smudski, J. F. The effect of an irrelevant drive on maze learning in the rat. J. exp. Psychol, $1957,54,148-152$.

Levine, S., Staats, S. A., \& Frommer, G. Drive summation in a water maze. Psychol. Rep., 1959, 5, 301-304.

Morey, $\mathbf{R} \mathbf{H}$. Swimming speed of rats as a function of the presence or absence of sound J. comp. Psychol., 1934, 17, 329-354.

sheet of acetate at $1 / 16$ in intervals; thus the grid contains 256 dots per square in. Greater or less accuracy can be obtained by decreasing or increasing the spacing of the dots.

The dot grid is placed over the cerebral cortical portion of the Lashley diagram and the number of dots falling within the figure are counted. Three readings are recommended to assure accuracy; an average of the readings may be taken in the event they do not agree. Bryan (1943) recommended counting every other dot that falls on the boundary line, but the present writers suggest equal accuracy will be obtained by counting all dots on the line of the brain diagram and on the line demarcating the lesion. The number of dots in the lesion divided by the number of dots in the brain diagram gives the per cent of cortex which has been removed.

\section{Discussion}

Abell (1939) reported that the dot grid method has $1.84 \%$ error compared to planimeter controls. It was not possible to discern from Abell's study whathis dot grid interval was. It is possible that the error is less in the dot grid spacing described here (i. e. 256 dots/sq in). In any event, a two per cent error is quite tolerable when the advantages in time, effort and expense are considered.

\section{heferences}

Abell, C. A. A method of estimating area in irregularly shaped and broken figures. J. Forestry, 1939, 37, 344-345.

Avery, T. E. Interpretation of aerial photographs. Minneapolis; Burgess Pub. Co., 1962

Bryan, M. M. Area determinations with the modified acreage grid J. Forestry, 1943, 41, 764-766.

Lashley, K. S. Brain mechanisms and intelligence. Chicago: University of Chicago Press, 1929

Robinson, A. H. Elements of cartography. New York: John Wiley \& Sons, 1953.

Spurr, S. H. Aerial photographs in forestry. New York: Ronald Press, 1948 